\title{
A Vehicle Shift and Positioning Systems for Joint Distribution of Containerized Logistics Postal
}

\author{
https://doi.org/10.3991/ijoe.v12i12.6459 \\ Y.H. Gao ${ }^{1}$ and T.Y.Chen ${ }^{2}$ \\ ${ }^{1}$ Chongqing Institute of Technology, Chongqing, China \\ ${ }^{2}$ No. 4 Institute of China Aerodynamics Research and Development Center, Mianyang, China
}

\begin{abstract}
In the process of postal containerized transport, some appropriate equipment should be applied for handling, transportation, storage, sorting and other aspects of the good due to the limitations of the compartment size, dynamic conditions, costs and other factors. According to the characteristics of the post containerized transport, three vertical displacement with left, middle and right position are setted on van body and a lateral shifting device is setted in the front and rear sides of the columns. The container can be shifted and positioned by the row box shifting program and the device consisted of vertical displacement, vertical position, horizontal shifting, vertical positioning and the rail system. The container loading and unloading in logistics distribution and the job requirements of containerized logistics transportation is meeted. The container shift is controlled by programmable logic controller (PLC) without artificial participation. The influence factors of human error are avoided.
\end{abstract}

Index Terms-Container logistics; Handling; Joint distribution; Postal

\section{INTRODUCTION}

The mail handling is a relatively heavy manual labor during the post production process. The traditional pouch and a lot of sparing parts hampered the automation of transportation and handling. The vessel and container insteading of the pouch has been widely used for many years at home. The postal container generally refers to a large box container for mails which can be used for exchange of rail, road, sea and air transport or between the city's post offices. The postal container improved the quality and efficiency of the postal production. The container unit needs to be handled in the car and train, or moved in trains and automobiles' compartment after containerized logistics post. If the container turnover such as container handling, transportation or moving depends on manpower completely, not only the labor intensity is big but also it is a costly and time-consuming business and even the human is unable to complete these jobs[1][2][3].

The advantage of post container transportation is that all goods, no matter how different in size, shape or performance, are loaded into standard containers. This provides a condition for the loading and unloading of mechanization and automation. The United States has developed a lot of post containers for trains, cars and ships carrying. Meanwhile a special vehicles for carrying containers is designed [4][5]. In the postal container handling operation, handling car, pulley cage containers or container tipping unloaded equipment are used widely.
The United States uses the robotic container transfer system. The trolley or tray is mainly applied for post container handling domestically. A pendulum slider mechanism was designed by Liu Li and et al for flipping postal container. This equipment can clamp the postal container and flip the box 120 to 135 degrees by using swing cylinder of dump truck. But it cannot complete compartment shifting and positioning operations in the car compartments [6] [7] [8]. Based on research and analysis of the postal containerized logistics joint distribution systems, we proposed a set of postal logistics joint distribution truck mounted shifting and positioning device which can be used for van self-loading vehicle. The device can be used for placing, locating and shifting the containers quickly in the compartment. In the joint contribution process, the container can be chosen to handle and shift at the same time. The reliable and high efficiency operation is ensured. In the abnormal situation that the container cannot be selected directly from the rear end of the compartment, the container can be selected by shifting box cyclically between the containers.

\section{The System DesigN}

The system is consisted of vertical displacement device, vertical positioning device, lateral displacement device, vertical positioning device, rail system, framework supporting structure, pneumatic system and control system and so on. The system architecture is shown in Figure 1.

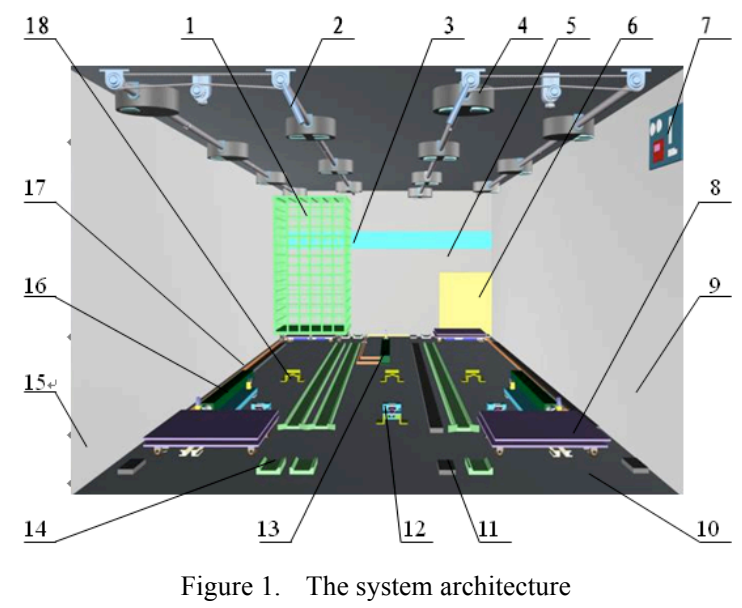

Here: 1- Containers, 2-Positing handle, 3-Front bezel, 4-Vertical clamping device, 5- The front of compartments, 6- Integrated boxes of pneumatic components, 7Manipulated panel, 8-Transverse displacement means (the front and end of the left and right columns all has one set 
of this device, 9- The right side panel of the compartments , 10-Cabin floor, 11- Track pad, 12- Vertical positioning device (the end of each column all has one set of this device), 13- Middle column longitudinal displacement means ,14 - Rail, 15- The left side panel of the compartments, 16-The sides of the column longitudinal displacement means, 17- Pipelines, 18- Seat vertical positioning device.

Considering low demands for motion accuracy and the goods cannot be polluted, the pneumatic is employed as power source. In the parking state the air source of trunk brake system is employed to provide pneumatic power for the device and new power device is not needed.

A manual start button is set at some appreciate place of the compartment to start handling the container. The container can be shifted alternately between the left and right column. The lateral column can also be selected artificially in some special cases. The cylinder operation is controlled by PLC and the power is provided by on-board electrical system. The control flow is shown in figure 2 .

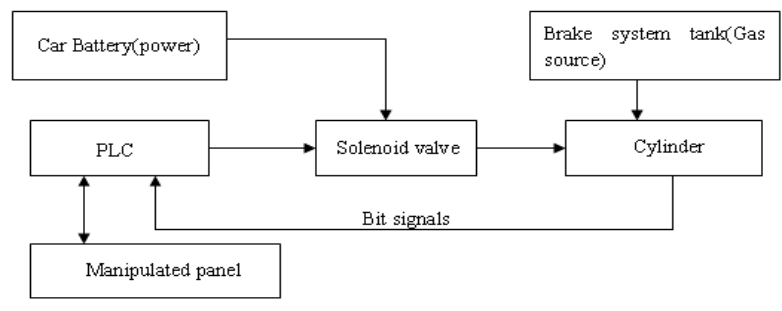

Figure 2. The Control System Diagram

\section{The Design OF MAIN Work Cell}

\section{A. Longitudinal displacement device}

The container in both sides of the column and the middle column can be displaced longitudinally based on the requirement of two containers in and one out by the longitudinal displacement device which structure is shown in Figure 3. The activity hook component, can be reciprocated with the piston of cylinder 1 , is forced down for suiting the bottom of the container when it is under the container. When moving to the back of carriage and shifting out the carriage, the activity hook component is straightened by the action of the spring. When moves to the front of carriage, the piston, puts the container in motion. In order to prevent the piston turning round, a guiding device is set up. In the absence of container, an accessory movable retractor 5 is employed to drive the container.

A pair of longitudinal displacement device is put in the back of container. When the first container make a lateral displacement movement, the longitudinal displacement device will pull the others container one step $(1100 \mathrm{~mm})$. Then the piston of the longitudinal displacement device hangs over to the initial position. When the container is not filled, a device for checking container absence is set up for the sake of normal operation.

The operation principle of middle container is the same as two side columns basically. The difference is the remaining five containers is longitudinal position by moving a step $(1100 \mathrm{~mm})$ to the back of carriage after a container at the back end of middle column is unloaded. Here the longitudinal displacement device is placed on the front of the middle column containers and the direction is the opposite of side column. Moreover the piston is back to the initial position when the side column container moves to the middle position laterally. Owing to the middle column container moves from the front to the back of carriage, the container absence check device in not needed.
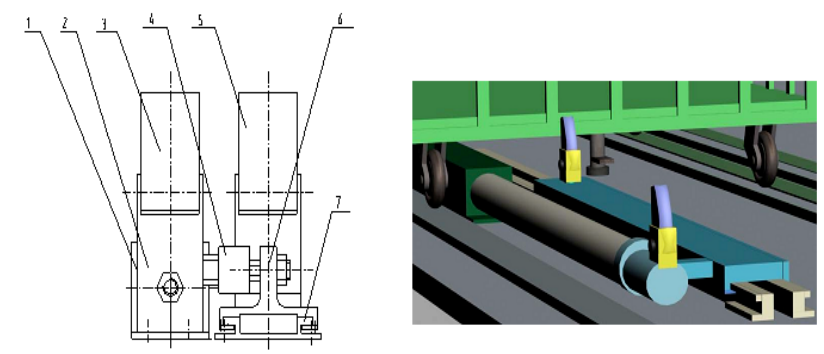

Figure 3. The longitudinal displacement device

1-Air cylinder,2-Retractor seat, 3-The main activities retractor, 4-Connecting nut, 5- Accessory activity retractor, 6-Guide seat, 7-Guiding Fitting.

\section{B. Vertical positioning device}

The vertical positioning device, used for straining and position container, is placed on the back of containers. The vertical positioning device is consisted of noumenon, eyebolt, the cylindrical pin, the cylindrical pin, clamp, gland nut and so on. Its structure is shown in figure 4 . The clamp 5 can fall down after gland nut 6 being relaxed and do not interfere with the container. The vertical positioning device can be fixed on the floor of the carriage and need not to move away when the container is loaded. More ever if there is absence of a container, it is easy to loosen the fixed nut and take down to other base.

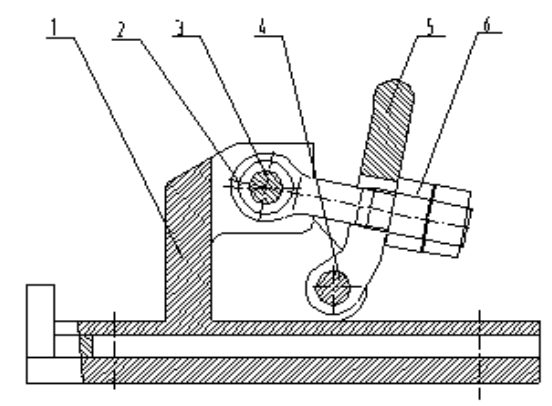

Figure 4. Vertical positioning device

1-noumenon,2-Eyebolt ,3-The cylindrical pin,4-The cylindrical pin,5-pressing plate, 6-gland nut

\section{Transverse displacement device}

The transverse displacement device is set up on the fron and back end of both sides of the container respectively for moving both sides container to middle column laterally and the opposite effect. The transverse displacement device structure is shown in figure 5 . When the container at the front of the middle column is pulled back a step by longitudinal displacement device, a container position is empty. Now the container at the front of the both side column works as follow. The cylinder 4 rises about $70 \mathrm{~mm}$ and the lifting plate holds up the container. Then the cylinder 7 moves the transverse displacement device and container to the middle direction 
$750 \mathrm{~mm}$ by the bottom plate. Here the cylinder 4 descends and the container is placed on the middle column guide rail. The cylinder 7 returns to the original position. The guide bar 3 is used to prevent the lifting plate turning round. The joint between cylinder 7 and bottom plate 5 is employed floating connector for guarantying the piston moves smoothly at surface roughness of carriage.

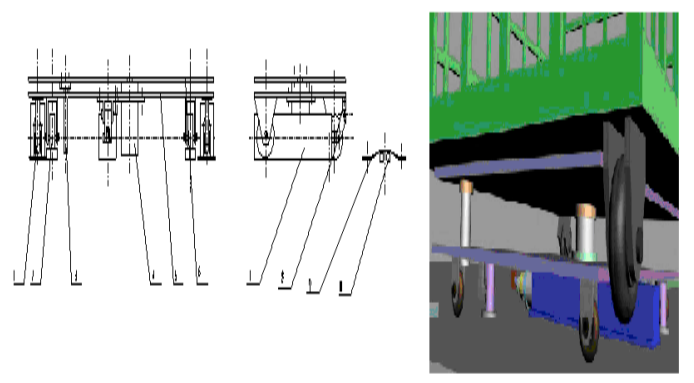

Figure 5. Transverse displacement device

1-Shock insurance device, 2-wheel, 3-guide bar, 4-Lifting cylinder, 5-bottom plate, 6-lifting board , 7-Lateral displacement of multilayered cylinder, 8floating terminals , 9-A line bridge, 10-Cylinder pipeline

An anti vibration device, shown in figure 5, is designed for preventing transverse displacement device damaging the cylinder 7 when the car bumps. When the transverse displacement device returns to the side column from the middle column, the pinch roller 6 touches on the bezel of guide 5 and moves to the axis of the guide cylinder 5 . At the influence of spring 3, the transverse displacement device is strained by pull road 2 .

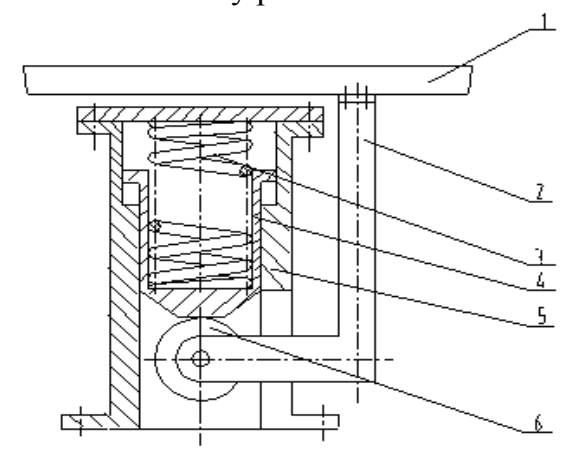

Figure 6. Quake insurance device

1-The tray Transverse displacement device, 2-pull road,3-spring, 4-endotheca, 5-guide, 6-pinch roller

\section{The vertical positioning device}

The function of the vertical positioning device is to stress the container and restrict the container freedom degree in the vertical direction. The structure of the vertical positioning device is shown in figure 6 . When finishing or starting handling container, the rubber springs on each pinch point rise or fall $90 \mathrm{~mm}$. The container is tightened or loosens. This device works on the principle of piston crank mechanism. Position handle 7 is turned round about 90 degree and universal shaft is rotated by Manual wrench. The crank 11 turns round and drives piston 14 straight reciprocating motion Thus the rubber spring 12 is tighten or loosen in the vertical direction.

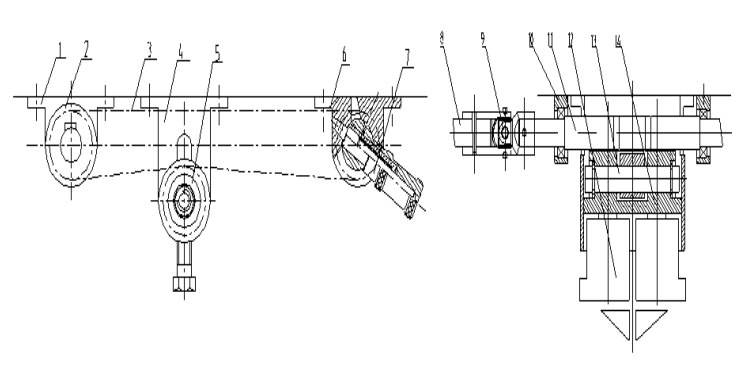

a. The actuating mechanism $\quad$ b. The piston pressing device

Figure 7. Figure 6 the vertical positioning device

1-Sprocket wheel seat,2-Sprocket, 3 - Roller chain, 4 Tension wheel, 5 - Tension wheel, 6 - Handle, 7 Positioning handle, 8 - Link rod, 9 - Universal shafts knot, 10 - Bearing, 11 - Crank, 12 - Rubber spring, 13 - Pin, 14 - Piston.

\section{THE SySTEM WORKFLOW}

\section{A. The container arrangement and shift in the carriage}

Before each batch delivery operation, the container should be loaded into the truck according to the predetermined sequence. During the transition, when the work handover in each logistics node, the middle column container, exactly required in the logistics network, is removed.

Take a van truck with length $*$ width $*$ height is $7300 \mathrm{~mm} * 2400 \mathrm{~mm} * 2400 \mathrm{~mm}$ as an example. Under the joint distribution, if a container with total weight $500 \mathrm{~kg}$ and $1100 \mathrm{~mm} * 750 \mathrm{~mm} * 1700 \mathrm{~mm}$ sizes (see figure 7 ) is unloaded in each joint point and another container is loaded to other logistics nodes, the key problem to be solved is how to arrange and shift container in the carriage. Three column containers with each column width $750 \mathrm{~mm}$ are set up along the direction of carriage width $(2400 \mathrm{~mm})$. As shown in figure $8.1,2, \ldots 18$ is the serial number of the logistics outlets respectively along the transport route. That is the serial number of unloaded container. For example container 1 is unloaded in logistics network 1 from the back door, container 2 is moved to position $\mathrm{B}$ from position $\mathrm{A}$, container 3 is moved to position $\mathrm{B}$ from position $\mathrm{C}$, container 4 is moved to position $\mathrm{C}$ from position $\mathrm{D}$, container 5 is moved to position $\mathrm{D}$ from position $\mathrm{E}$, container 6 is moved to position $\mathrm{E}$ from position $\mathrm{F}, \ldots .$. , container 17 is moved to position $\mathrm{O}$ from position $\mathrm{Q}$, Position $\mathrm{Q}$ is empty. Thus the container from this logistics point can be sent to position Q. When container 2 is unloaded, position $\mathrm{R}$ can be empty by the above method. The rest can be done in the same manner. All containers can be shifted. Here the transverse shift of container is carried out alternately by right and left column. In order to avoid artificial error, the shift carries on automatically and without artificial. Only when the container arrangement is abnormal, the operator controls the middle column containers to shift to the left or right column transversely by manipulating PLC manually. The cyclic shift is formed shown in figure 2-3 with arrow $\mathrm{A}$ and $\mathrm{Y}$. 

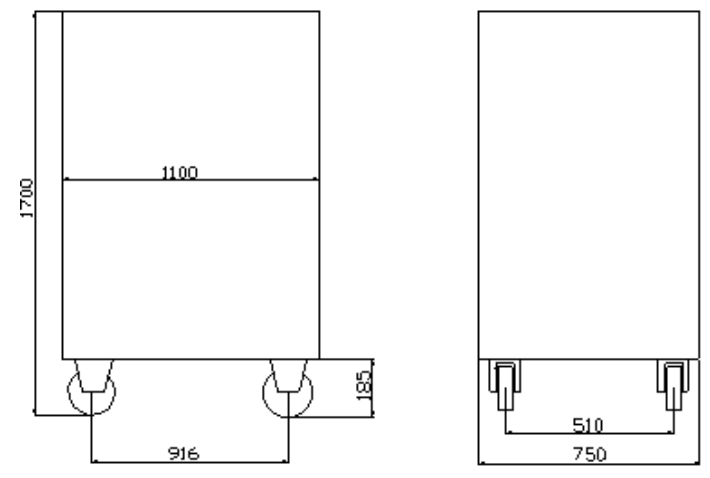

Figure 8. Container sketch

the $\mathrm{X}$ direction of cycle front end (cab) the $\mathrm{Y}$ direction of cycle

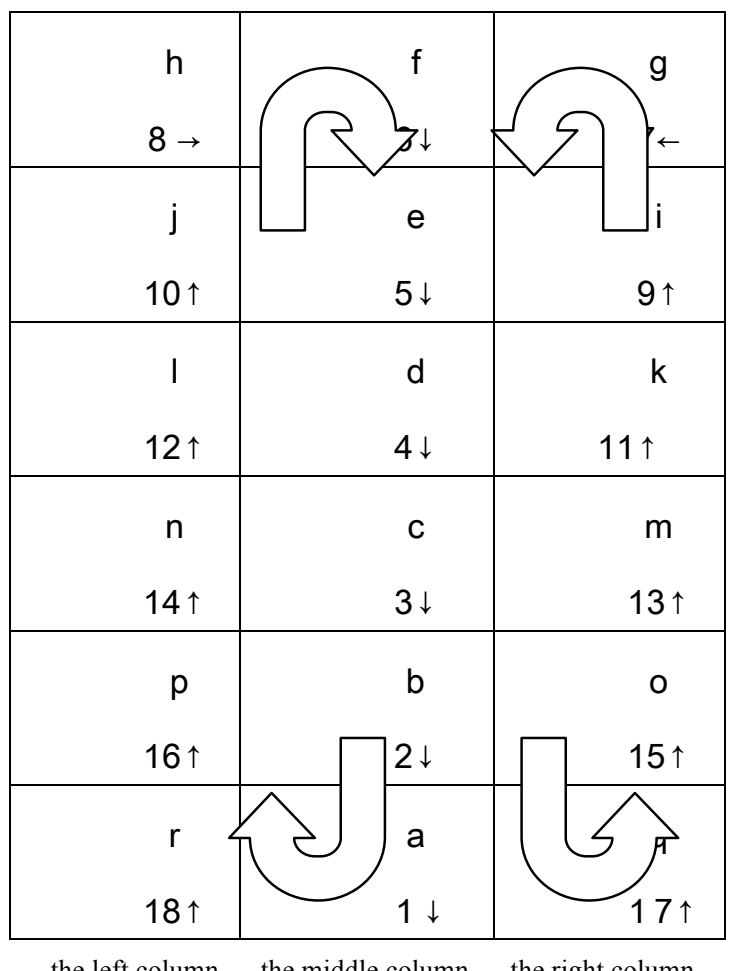

Train the back-end

Figure 9. The principle diagram of the container arrangement and shift

\section{B. The container handling}

A lifting device assembled on the back of the trunk is employed to raise the container to the carriage or unload the container. When loaded, the container is pushed into the last position of left or right column by artificial, just as position $\mathrm{R}$ and $\mathrm{Q}$ in figure 8 .

In order to avoid the interference between container brake and transverse displacement device, Straight row wheel is in the former and universal wheel and brake follow.

\section{CONCLUSION}

The postal container has the advantages of simplifying the mail process, reducing the mail damaged effectively, simplifying the mail dispatching handover and improving production efficiency. The joint distribution of containerized logistics postal is a large system consisted of hundreds of logistics network and consumption points with multipath, multiple batches and multi mode transition. To meet the requirements of container loading and unloading transportation, not only the container dimension chain is need to optimize for improving space utilization ratio of transport vehicles and container vessel, but also the container lorry shift and positioning system should be applied to meet the demand of the loading and unloading in different occasions. The container shift and positioning system presented in this paper is easy to use and has low maintenance cost. It reduces the labor intensity of workers significantly.

\section{REFERENCES}

[1] L. Xue, X. Q. Lang, The practice and exploration of pallet postal transportation, China Post, Vol. 11, pp.54-55, 2010

[2] H. B. Shi, The practice and exploration of the postal container reform, China Post, Vol. 10, pp. 10:50-51, 2008.

[3] Y. H. Fan, H. O. Luo, Study on Inner Postal District Transportation Scheme Using Container, Studies on Posts, Vol. 21, pp.34-36, 2005.

[4] L. P. He, New Developments of Robots Application in USPS, Studies on Posts, Vol. 19, pp. 45, 2003.

[5] N. Ji, Discussion on the problems and development of China Postal Logistics, Modern Enterprise Education, Vol. 7, pp. 347$348,2013$.

[6] L. Liu, Q. Z. Niaon, Design of a Rocker-Slider Mechanism Used in Post Container Tip Machine, Mechanical Science and Technology, Vol. 20, pp. 324-325,2001.

[7] Q. J. Wu, Mail Center Equipment Technology Development, Designing Techniques of Posts and telecommunications, Vol. 1, 46-52, 2004.

[8] L. Chen, J. H. Zhen, The research of postal express mail shipping container, Studies on Posts, Vol. 25, pp. 27-29, 2009.

[9] S. R. Zheng, A Study of Questions and Countermeasure in Post Matter-flow Operational Management, Journal of Hunan Business College, Vol. 12, pp. 43-45, 2005.

\section{AUTHORS}

Y. H. Gao is with the School of Mechanical Engineering, Chongqing Institute of Technology, Chongqing China (email: guangchi@foxmail.com).

T. Y. Chen is with No. 4 Institute of China Aerodynamics Research and Development Center, Mianyang China (email: wx_cty@163.com).

Submitted 26 October 2016. Published as resubmitted by the authors 27 November 2016. 